\title{
Generation of an anti-angiogenic endothelial progenitor cell line via endostatin gene transfer
}

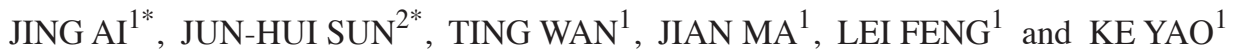 \\ ${ }^{1}$ Eye Centre, The Second Affiliated Hospital of The School of Medicine, Zhejiang University, Hangzhou, \\ Zhejiang 310009; ${ }^{2}$ Key Laboratory of Combined Multi-Organ Transplantation, Ministry of Public Health, \\ The First Affiliated Hospital of The School of Medicine, Zhejiang University, Hangzhou, Zhejiang 310003, P.R. China
}

Received May 26, 2017; Accepted September 8, 2017

DOI: $10.3892 / \mathrm{mmr} .2018 .8623$

\begin{abstract}
The viability of endothelial progenitor cells (EPCs) as a therapeutic treatment for neovascularization (NV) was subject to investigation in the present study. Furthermore, endostatin has previously been demonstrated to be an inhibitor of angiogenesis and a suppressant of vascular leakage. The aim of the present study was to generate transgenic EPCs with anti-angiogenic effects for the treatment of ocular NV. EPCs were obtained from rat peripheral blood samples and then verified. A lentiviral-endostatin-green fluorescent protein recombinant construct was generated and used to infect EPCs. Transfected cells were then subjected to puromycin selection. Reverse transcription-quantitative polymerase chain reaction and a western blot assay were then applied in order to determine both the endostatin mRNA and protein expression levels, respectively. In addition, vascular endothelial growth factor (VEGF) expression levels were also detected in order to observe the anti-angiogenic effect of the endostatin-transfected EPCs. Following puromycin $(1 \mu \mathrm{g} / \mathrm{ml})$ selection for 4 days, a stable endostatin-transfected EPC line was generated. In this stable endostatin-transfected EPC line, the expression levels of endostatin increased; whereas the expression levels of VEGF decreased. The results of the present study revealed that EPCs can be genetically modified to overexpress endostatin, which may provide the cells with an anti-angiogenic effect via increased expression of endostatin and decreased expression of VEGF. Thus, EPCs genetically modified to overexpress endostatin may serve as a potential therapeutic agent for ocular NV treatment.
\end{abstract}

Correspondence to: Professor Ke Yao, Eye Centre, The Second Affiliated Hospital of The School of Medicine, Zhejiang University, 88 Jiefang Road, Hangzhou, Zhejiang 310009, P.R. China

E-mail: xlren@zju.edu.cn

${ }^{*}$ Contributed equally

Key words: endostatin, gene transfer, endothelial progenitor cells, lentiviral vector

\section{Introduction}

Ocular neovascularization (NV) is the primary cause of blindness in a wide range of ocular diseases, including diabetic retinopathy and age-related macular degeneration among others (1). Endothelial progenitor cells (EPCs) have been experimentally and clinically verified as a contributor to both re-endothelialization and NV processes (2-4). EPCs are implicated in an early stage of embryogenesis and express a broad range of endothelial markers, including fetal liver kinase-1 (FLK-1) and low-density lipoprotein (LDL) receptor, which are integrated in the newly formed blood vessels during vasculogenesis and angiogenesis.

In addition, endostatin is a cytokine that was first discovered as a secretory product in the media of non-metastasizing mouse cells. Endostatin is a $20 \mathrm{kDa} \mathrm{C}$-terminal fragment of collagen XVIII, and is an endogenous inhibitor of angiogenesis $(5,6)$. Endostatin may constitute a potent anti-angiogenic molecule for treating ocular NV. Endostatin inhibits endothelial cell proliferation, particularly in vitro, and inhibits angiogenesis and tumor growth in animal models (5). However, large-scale protein production is required in order to achieve a therapeutic effect with regards to angiogenesis inhibition. Exogenous endostatin protein has a short half-life in circulation, low peptide stability in vivo and is costly, thus the clinical applications of exogenous endostatin have been limited (7). Gene therapy may be the best way to explore practical application of endostatin in anti-angiogenesis. A previous study revealed that intravitreous injection of adenoviral vector samples containing sig-mEndo transgenes, in order to increase endostatin amounts, reduced laser-induced choroidal NV and retinal NV in a mouse model (8).

Both EPCs and endostatin are implicated in NV. EPCs genetically modified with endostatin may represent an effective therapeutic intervention strategy for the treatment of patients with ocular NV. However, in order for a gene-delivery system to be successful, highly efficient gene transfection and stable, long-term expression of the proteins are required. Therefore, the present study aimed to investigate the possibility of the generating a stable effective transfection of endostatin in EPCs, and to detect the vascular endothelial growth factor (VEGF) secretion for the observation of the anti-angiogenic effect of endostatin-transfected EPCs. 


\section{Materials and methods}

Ethics statement. All of the animal experiments in the present study were approved by the Institutional Animal Care and Ethics Committee of Zhejiang University (Hangzhou, China). All surgeries were performed under anesthesia and all possible efforts were made to minimize animal discomfort and stress. The methods in the present study were performed in accordance with approved guidelines and regulations.

EPC culture. EPCs were cultured according to our previous study (9). Five Sprague-Dawley rats (age, 2-3 months; 3 male and 2 female; 250-300 g; Laboratory Animal Centre of Zhejiang University, Hangzhou, China) were kept in a $12 \mathrm{~h}$ light/dark cycle at $22 \pm 1^{\circ} \mathrm{C}, 50-60 \%$ humidity with free access to food and water. Animals were fasted $12 \mathrm{~h}$ before the experiment and were given no water on the day of the experiment. Rats were anesthetized for 10 min prior to each experiment via intraperitoneal injection of sodium pentobarbital (Merck KGaA, Darmstadt, Germany) at a dose of $30 \mathrm{mg} / \mathrm{kg}$. Following this, $5 \mathrm{ml}$ of peripheral blood was collected from the right ventricle of each anesthetized rat. Post-blood collection, the rats were then sacrificed and their carcasses were handled in accordance with approved guidelines. The blood samples were heparinized, diluted with phosphate buffer saline and then separated using Ficoll solution (GE Healthcare Bio-Sciences, Pittsburgh, PA, USA). The layer of peripheral blood mononuclear cells was isolated via density centrifugation, and was then re-suspended in EGM-2MV medium (Lonza Group, Ltd., Basel, Switzerland) within a fibronectin-coated vessel. Unattached cells were subsequently removed following 4 days of culture at $37^{\circ} \mathrm{C}$ and then periodically removed every 2 days thereafter. At $80-90 \%$ confluence, the cells were trypsinized using $0.25 \%$ trypsin (Solarbio Life Sciences, Beijing, China) and then sub-cultured for 7 days onto glass cover slips at $\sim 1 \times 10^{5}$ cells $/ \mathrm{cm}^{2}$.

EPC characterization. Following sub-culture, the cells were then incubated with 1,1-dioctadecyl-3,3,3',3'-tetramethylindocarbocyanine-labeled acetylated LDL (Dil-Ac-LDL; $12 \mu \mathrm{g} / \mathrm{ml}$; cat. no. L3484; Thermo Fisher Scientific, Inc., Waltham, MA, USA) for $10 \mathrm{~h}$ at room temperature in dark. Subsequently, cells were fixed by $4 \%$ polyoxymethylene at room temperature for $20 \mathrm{~min}$ and counterstained with fluorescein isothiocyanate-conjugated Ulex europaeus lectin (FITC-UEA-1; $10 \mu \mathrm{g} / \mathrm{ml}$; cat. no. L9006; Sigma-Aldrich; Merck KGaA) for $1 \mathrm{~h}$ at room temperature. Nuclei were counterstained with DAPI (cat. no. C1002; $0.1 \mu \mathrm{g} / \mathrm{ml}$; Beyotime Institute of Biotechnology, Shanghai, China) at room temperature for $10 \mathrm{~min}$. Micrographs were acquired by fluorescence microscopy (magnification, x100) (Motic Incorporation, Ltd., Causeway Bay, Hong Kong). Cells with double-positive fluorescence were considered to be EPCs. Following staining, the total number of double-positive Dil-Ac-LDL/FITC-UEA-1 cells was calculated by counting the cells in each visual field, which were then expressed as the percentage of EPCs marked positive for merged Dil-Ac-LDL/FITC-UEA-1 dual staining. In addition, flow cytometry was used to analyze the expression of CD34 and CD133 progenitors, as well as FLK-1 and CD31 endothelial lineage markers (10-14). Cells were harvested and washed with ice cold PBS. Cells were subsequently blocked with 10\% goat serum (cat. no. SL038; Beijing Solarbio Science \& Technology Co., Ltd., Beijing, China) at room temperature for 30 min. Anti-CD34 (cat. no. sc-7324; dilution 1:200; Santa Cruz Biotechnology, Inc., Dallas, TX, USA), anti-CD133 (cat. no. 18470-1-AP; 1:500; ProteinTech Group, Inc., Chicago, IL, USA) and anti-FLK-1 (cat. no. ab2349; dilution 1:1,000; Abcam, Cambridge, UK) primary antibodies were incubated with the cells at $4^{\circ} \mathrm{C}$ for $2 \mathrm{~h}$. Subsequently, cells were washed with PBS and incubated with the phycoerythin-conjugated goat anti-rabbit IgG (cat. no. sc-3739; 1:200; Santa Cruz Biotechnology, Inc.) or fluorescein isothiocyanate (FITC)-conjugated goat anti-mouse IgG secondary antibodies (cat. no. sc-2010; 1:200; Santa Cruz Biotechnology, Inc.), or incubated directly with FITC-conjugated anti-CD31 primary antibody (cat. no. ab33858; $1: 100$; Abcam) at $4^{\circ} \mathrm{C}$ for $30 \mathrm{~min}$ in the dark. Finally, the cells were washed with PBS and resuspended in PBS; $1 \times 10^{6}$ cells $(20 \mu \mathrm{l})$ were used each time. Passage 3 cultures were used for all experiments. Quantitative fluorescence analysis was performed with a FACSCalibur flow cytometer (BD Biosciences, Franklin Lakes, NJ, USA), and the data was analyzed with CellQuest Pro software (version 5.1; BD Biosciences).

Endostatin expression plasmid construction. The endostatin fragment was amplified between the NotI and BamHI restriction sites via polymerase chain reaction (PCR) using the following primer sequences: B2085CEF, 5'-AGGGTTCCA AGCTTAAGCGGCCGCGCCACCATGCATACTCATCAG GAT-3' and B2085CER, 5'-ATCAGTAGAGAGTGTCGG ATCCTtatt TGgaga A AGAGgtCATGA AG-3'. Pfu DNA polymerase (cat. no. D7216; $0.3 \mu \mathrm{l}$; Beyotime Institute of Biotechnology) was used and the thermocycling conditions were as follows: $95^{\circ} \mathrm{C}$ for $3 \mathrm{~min}$; followed by 30 cycles of $94^{\circ} \mathrm{C}$ for $30 \mathrm{sec}, 55^{\circ} \mathrm{C}$ for $30 \mathrm{sec}$ and $72^{\circ} \mathrm{C}$ for $30 \mathrm{sec}$ and final extension at $72^{\circ} \mathrm{C}$ for $5 \mathrm{~min}$. The product was then verified via DNA sequencing. The endostatin fragment was subsequently cloned into a lentiviral (LV) vector [LV5-EF1a-green fluorescent protein (GFP)+PURO] (Shanghai GenePharma Co., Ltd., Shanghai, China) using ClonExpress ${ }^{\circledR}$ Entry One Step Cloning kit (cat. no. C114; Vazyme Biotech Co., Ltd., Nanjing, China) for $30 \mathrm{~min}$ at $37^{\circ} \mathrm{C}$. The recombinant LV vector (LV5-EF1a-GFP+PURO-Endostatin) was then produced via co-transfection of $293 \mathrm{~T}$ cells with three plasmids [pLV/helper-SL3 (4 $\mu \mathrm{g})$, pLV/helper-SL4 (4 $\mu \mathrm{g})$, pLV/helper-SL5 $(4 \mu \mathrm{g})]$ and endostatin plasmid $(4 \mu \mathrm{g})$ using Lipofectamine ${ }^{\circledR} 2000$ reagent (Thermo Fisher Scientific, Inc.) for $24 \mathrm{~h}$ at $37^{\circ} \mathrm{C}$. The medium was then changed and following $48 \mathrm{~h}$ of further incubation, cell culture supernatants were then collected and centrifuged at $2,500 \mathrm{x}$ g for $15 \mathrm{~min}$ at $37^{\circ} \mathrm{C}$. The recombinant $\mathrm{LV}$ vector solution was then concentrated and stored at $-80^{\circ} \mathrm{C}$. Following flow cytometric assessment for GFP levels, vector titers were expressed as transduction units per ml.

Stable transduction of EPCs. At 80-90\% confluence, the primary EPCs were transferred into 6-well plates at $1 \times 10^{6}$ cells/well for lentiviral transduction. A medium containing the lentiviral vector (LV-Endostatin-GFP) and polybrene (5 $\mu \mathrm{g} / \mathrm{ml}$; Merck KGaA, Germany) was added at a 
multiplicity of infection of 100 in order to improve infection efficiency, and then mixed with the cells. Following incubation for $24 \mathrm{~h}$, the cell culture medium was then removed and replaced with Dulbecco's modified Eagle's medium (Hyclone; GE Healthcare Life Sciences, Logan, UT, USA) supplemented with $10 \%$ fetal bovine serum. At $80-90 \%$ confluence, the transfected EPCs and control cells were subjected to puromycin $(1 \mu \mathrm{g} / \mathrm{ml})$ selection. Cells transduced with LV-Endostatin-GFP were subsequently used as the endostatin overexpression (OE) groups. Cells that did not undergo transduction were used as the blank control groups. Cells transduced with GFP alone were used as the negative control (NC) groups.

RNA extraction. Total RNA was obtained from EPCs by phenol-chloroform extraction and ethanol precipitation using the TRIzol reagent (Thermo Fisher Scientific, Inc.) following the manufacturer's protocol. RNA quantities and purities were determined spectrophotometrically using a Nano Drop ${ }^{\circledR}$ instrument (Thermo Fisher Scientific, Inc.), and RNA purity was further assessed by determining the optical density (OD) ratio at 260:280 $\mathrm{nm}$. RNA integrity was determined by $1 \%$ agarose gel electrophoresis and visualized with ethidium bromide $(0.5 \mu \mathrm{g} / \mathrm{ml})$.

Reverse transcription-quantitative polymerase chain reaction (RT-qPCR). RT-qPCR was used for the determination of endostatin and VEGF gene expression levels. Reverse transcription to cDNA was performed using the Takara PrimeScript ${ }^{\circledR}$ RT Reagent kit (Takara Biotechnology Co., Ltd., Dalian, China). The reaction conditions were as follows: $42^{\circ} \mathrm{C}$ for $30 \mathrm{~min}$ and $85^{\circ} \mathrm{C}$ for $10 \mathrm{~min}$. PCR was performed using SYBR Premix Ex Taq ${ }^{\mathrm{TM}}$ II (TliRNaseH Plus; cat. no. RR820A; Takara Biotechnology Co., Ltd.) according to the manufacturer's instructions. Taq DNA polymerase (cat. no. MB3408; $2.5 \mathrm{U} / \mu \mathrm{l}$; Melone Biological Technology Co., Ltd., Dalian, China) was used with the following thermocycling conditions: $95^{\circ} \mathrm{C}$ for $3 \mathrm{~min}$, followed by 40 cycles of $95^{\circ} \mathrm{C}$ for $12 \mathrm{sec}$ and $62^{\circ} \mathrm{C}$ for $40 \mathrm{sec}$. The bands were normalized using GAPDH as a housekeeping gene control (internal control). The relative expression levels of endostatin genes were quantified with the $2^{-\Delta \Delta C q}$ method (15). The following primers were used: endostatin forward, 5'-TCTCCCAAGTCGAAGACCCT-3' and reverse, 5'-GAACAGCAGCGAAAAGTCCC-3'; VEGF forward, 5'-GTGAGCCTTGTTCAGAGCG-3' and reverse, 5'-GACGGT GACGATGGTGG-3'; GAPDH forward, 5'-TCTCTGCTCCTC CCTGTTCT-3' and reverse, 5'-ATCCGTTCACACCGACC TTC- 3 '. PCR was performed in triplicate in each cDNA sample.

Western blot assay. The expression levels of endostatin and VEGF proteins in the supernatants of cell cultures were determined using a western blot assay. EPCs were lysed with radioimmunoprecipitation assay lysis buffer (cat. no. P0013; Beyotime Institute of Biotechnology). Total protein was obtained from the supernatants of cell lysates and the concentration was determined with a bicinchoninic acid protein assay kit. Samples were subjected to SDS-PAGE loading buffer, heated at $100^{\circ} \mathrm{C}$ for $5 \mathrm{~min}$, cooled and then centrifuged at $10,000 \mathrm{x} \mathrm{g}$ for $10 \mathrm{~min}$. Equal amounts of protein $(20 \mu \mathrm{g})$ were resolved by $10 \%$ SDS-PAGE, electro-transferred onto polyvinylidene difluoride membranes (EMD Millipore,
Billerica, MA, USA), and blocked with Tris-buffered saline containing $0.05 \%$ Tween-20 and 5\% non-fat dry milk at room temperature for $2 \mathrm{~h}$. Membranes were then incubated with primary mouse anti-endostatin antibody (dilution 1:1,000; cat. no. ab64569; Abcam) and rabbit anti-rat VEGF antibody (dilution 1:1,000; cat. no. 19003-1-AP; ProteinTech Group, Inc.) at $4^{\circ} \mathrm{C}$ overnight. Following rinsing with Tris-buffered saline containing Tween-20 (TBST; China National Pharmaceutical Group Corporation, Beijing, China), then with horseradish peroxidise-conjugated goat anti-rabbit or goat anti-mouse $\mathrm{IgG}$ secondary antibodies [dilution 1:20,000; cat. nos. GAR0072 and GAM0072, respectively; MultiSciences (Lianke) Biotech, Co., Ltd., Hangzhou, China] for $2 \mathrm{~h}$ at $37^{\circ} \mathrm{C}$. Protein expression was normalized to GAPDH and expressed as relative densitometry units. Detection of immunoreactive bands was carried out using the Enhanced Chemiluminescence System (GE Healthcare Bio-Sciences). Gel-Pro Analyzer software (version 4; Media Cybernetics, Inc., Rockville, MD, USA) was used for data analysis.

Statistical analysis. SPSS version 19.0 software (IBM Corp., Armonk, NY, USA) was used to analyze all data via one-way analysis of variance followed by a Least Significant Difference post-hoc test. All data were expressed as the mean \pm standard deviation. $\mathrm{P}<0.05$ was considered to indicate a statistically significant difference. Each in vitro experiment was repeated at least three times.

\section{Results}

Characterization of EPCs. EPCs are able to take up Dil-Ac-LDL and FITC-UEA-1, the levels of which were demonstrated by fluorescent staining. Nuclei counterstained with DAPI produced blue fluorescence. Positive staining with Dil-Ac-LDL and FITC-UEA-1 produced red fluorescence and green fluorescence, respectively; double-positive Dil-Ac-LDL and FITC-UEA-1 appeared as yellow fluorescence staining. The percentage of double positive cells in the total number of cells was $98.87 \pm 0.29 \%$ (Fig. 1).

The expression levels of CD34, CD133, CD31 and FLK-1 EPC surface markers were investigated using flow cytometry. Flow cytometry revealed that the expression levels of $\mathrm{CD}^{+} 1^{+} / \mathrm{FLK}^{-}, \mathrm{CD} 31^{-} / \mathrm{FLK} 1^{+}, \mathrm{CD} 34^{+} / \mathrm{CD} 133^{-}$, and $\mathrm{CD}^{2} 4^{-/ \mathrm{CD} 133^{+}}$were $9.91 \pm 1.20,2.94 \pm 0.75,9.03 \pm 1.35$, and $0.65 \pm 0.19 \%$, respectively. The $\mathrm{CD} 34^{+} / \mathrm{CD} 133^{+}$double-positive cells rate amounted to $90.32 \pm 1.18 \%$, and the $\mathrm{CD} 31^{+} / \mathrm{FLK}-1^{+}$ double-positive cells rate amounted to $87.16 \pm 0.96 \%$ (Table I; Fig. 2).

RNA integrity, purity and concentration. RNA integrity was confirmed with the clear bands at 28s ribosomal (r)RNA and 18s rRNA markers on agarose gels. RNA purity was reflected by an OD 260:280 nm value of 1.9-2.2 (Fig. 3).

Endostatin expression. Compared with the NC group, the endostatin mRNA expression of the OE group was significantly increased $(\mathrm{P}<0.001)$. However, there was no significant difference in the mRNA expression between the blank control group and NC group (Fig. 4A). Fig. 4B and C present the results of the western blot assay. Compared with the NC group, the 

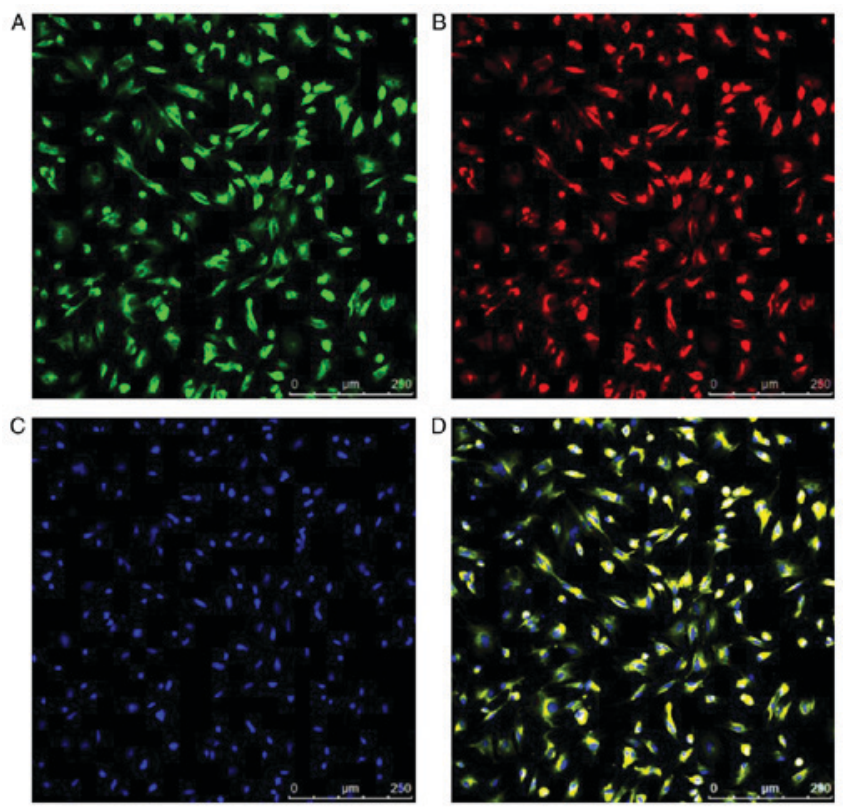

Figure 1. Characterization of EPCs using fluorescence microscopy. (A) FITC-UEA-1 positive cells identified by fluorescence staining with FITC-UEA-1. (B) Dil-Ac-LDL stained cells. (C) Nuclei counterstained with DAPI (D) Merged panels to reveal double-positive staining with Dil-Ac-LDL and FITC-UEA-1. EPCs, endothelial progenitor cells; FITC-UEA-1, fluorescein isothiocyanate-conjugated Ulex europaeus lectin; Dil-Ac-LDL, 1,1-dioctadecyl-3,3,3',3'-tetramethylindocarbocyanine-labeled acetylated low-density lipoprotein.

endostatin protein expression of the OE group increased significantly $(\mathrm{P}<0.01)$. However, there was no difference in endostatin protein expression between the blank control and $\mathrm{NC}$ groups.

VEGF expression. Fig. 4A presents the results of VEGF mRNA expression analysis. Compared with the NC group, VEGF mRNA expression of the OE group decreased significantly $(\mathrm{P}<0.05)$. However, there was no significant difference in the level of VEGF mRNA expression between the blank control and NC groups. Fig. 4B and C present the results of VEGF protein expression levels. Compared with the NC group, VEGF protein expression of the OE group decreased significantly $(\mathrm{P}<0.01)$. However, there was no significant difference in the level of VEGF protein expression between the blank control and NC groups.

\section{Discussion}

EPCs are considered to be circulating cells with significant pathological and therapeutic properties. EPCs have the ability to migrate to areas where NV occurs, and participate in either NV or endothelial repair. Such cells contribute to neovasculature by differentiating into endothelial cells (ECs) via the process of vasculogenesis (16), which contributes to postnatal vascular remodeling and NV (17-20). Despite EPCs contributing to $\mathrm{NV}$, it is yet to be investigated whether or not a transplant of normal healthy EPCs has the potential to aggregate NV of diabetic retinopathy (21). In addition, ischemic vascular damage may be repaired by healthy and nondiabetic EPCs (22). Furthermore, intravitreal injections of EPCs have been confirmed to rescue degenerated retinas; healthy EPCs
Table I. Flow cytometry analyses of endothelial progenitor cell surface markers.

A, FITC-CD31/PE-FLK1 antibodies

Cell type

Percentage (mean \pm standard deviation)

\begin{tabular}{|c|c|}
\hline CD31-FLK1' & $0.00 \pm 0.00$ \\
\hline $\mathrm{CD} 1^{+} \mathrm{FLK}^{-}$ & $9.51 \pm 1.03$ \\
\hline $\mathrm{CD}_{1}{ }^{-\mathrm{FLK}{ }^{+}}$ & $3.03 \pm 0.25$ \\
\hline $\mathrm{CD} 31^{+} \mathrm{FLK} 1^{+}$ & $87.46 \pm 1.20$ \\
\hline
\end{tabular}

B, FITC-CD34/PE-CD133 antibodies

Cell type

Percentage (mean \pm standard deviation)

$\begin{array}{lr}\mathrm{CD}^{-}{ }^{-} \mathrm{CD} 133^{-} & 0.00 \pm 0.00 \\ \mathrm{CD}^{-} 4^{+} \mathrm{CD} 133^{-} & 9.27 \pm 0.55 \\ \mathrm{CD}^{-} 4^{-} \mathrm{CD} 133^{+} & 0.55 \pm 0.16 \\ \mathrm{CD}^{+} 4^{+} \mathrm{CD} 133^{+} & 90.18 \pm 0.54\end{array}$

FITC, fluorescein isothiocyanate; CD, cluster of differentiation; PE, phycoerythrin; FLK, fetal liver kinase-1.
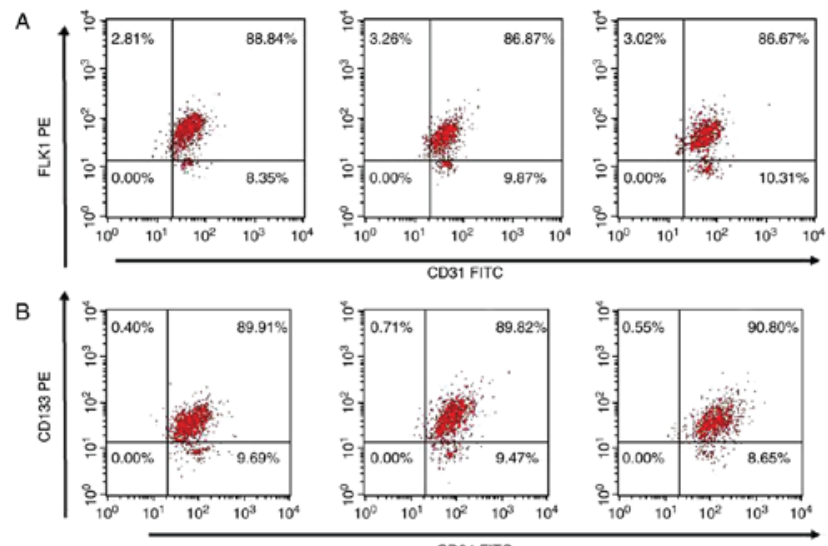

Figure 2. Determination of the expression of EPC surface markers via flow-cytometry. (A) CD31 and FLK-1 expression, and (B) CD34 and CD133 expression. EPCs, endothelial progenitor cells; FITC, fluorescein isothiocyanate; PE, phycoerythrin; FLK-1, fetal liver kinase-1; CD, cluster of differentiation.

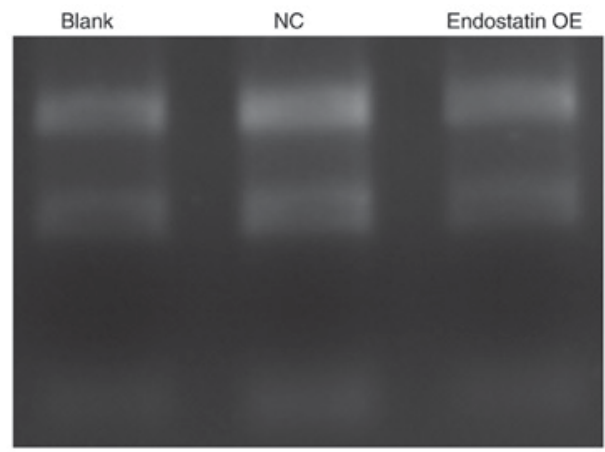

Figure 3. Extracted RNA from transfected EPCs. Bands were clear at $28 \mathrm{~s}$ rRNA and 18s rRNA on the electrophoregram. EPCs, endothelial progenitor cells; blank, blank control group; NC, negative control group; Endostatin OE, endostatin-overexpression group; r, ribosomal. 


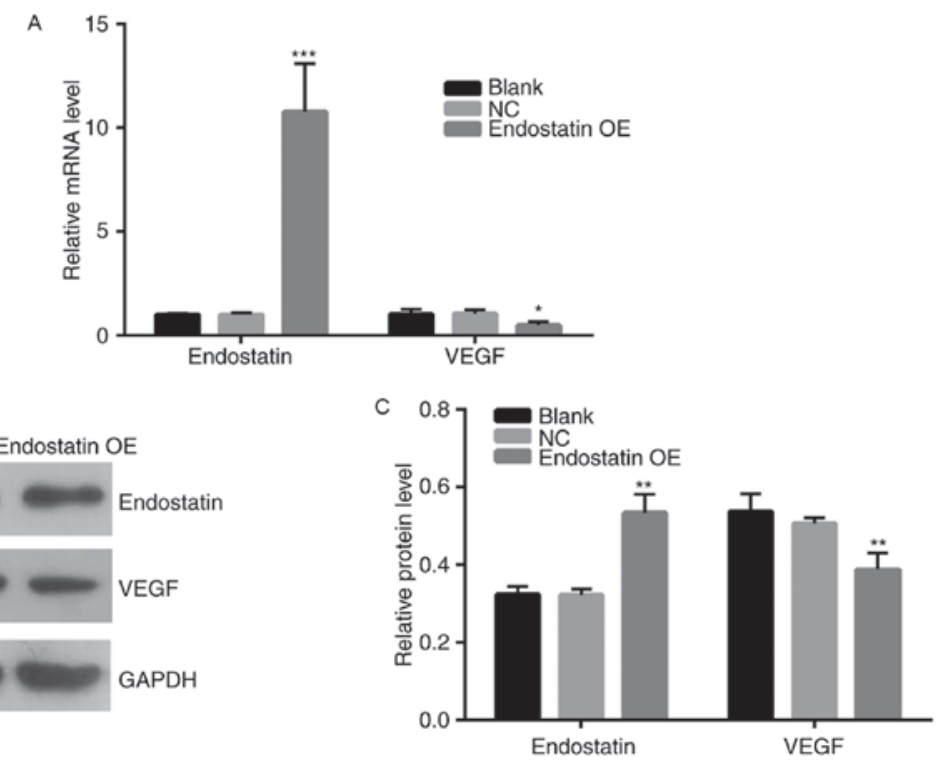

Figure 4. Expression of endostatin and VEGF in endostatin-transfected EPCs. (A) Relative mRNA expression levels of endostatin and VEGF determined by reverse transcription-quantitative polymerase chain reaction. (B) Endostatin and VEGF protein expression levels quantified via band-intensity analysis, GAPDH protein served as an internal control. (C) Relative protein expression levels of endostatin and VEGF determined via western blot assay, as compared with NC. "P $<0.05,{ }^{* * *} \mathrm{P}<0.01,{ }^{* * * *} \mathrm{P}<0.001$. EPCs, endothelial progenitor cells; blank, blank control group; NC, negative control group; Endostatin OE, endostatin-overexpression group; VEGF, vascular endothelial growth factor.

may repair unhealthy NV tissue and indirectly inhibit ocular NV (23). EPCs can be purified, expanded in vitro and administered to patients as autologous cells to revascularize ischemic tissues. Thus, EPCs may serve as a potential therapeutic agent for use in future clinical therapy.

The present study successfully isolated and cultured EPCs in vitro, and determined the typical expression levels of EPC surface markers (CD34, CD133, CD31 and FLK-1). CD133 is the most promising candidate for use as a specific EPC marker, as it is expressed solely in early EPCs and lost once the EPCs have differentiated into mature ECs (10-14). Furthermore, differentiating EPCs have the ability to take up Dil-Ac-LDL and FITC-UEA-1 simultaneously $(12,24)$, and the present study demonstrated that the Dil-Ac-LDL and FITC-UEA-1 double-positive staining percentage of EPCs was $98.87 \pm 0.29 \%$, therefore verifying that the cultured cells were in fact differentiating EPCs.

Furthermore, the present study also successfully developed an endostatin overexpressing EPC line for increasing long-term expression of endostatin, which has previously been revealed to be an endogenous inhibitor possessing anti-angiogenic activity, and to be responsible for suppressing retinal vascular leakage $(25,26)$. Endostatin administration may offer an innovative, preventative pharmaceutical strategy for ocular NV, whilst demonstrating anti-tumor effects when delivered continuously $(27,28)$. However, the use of endostatin in clinical trials for NV therapy has previously been hindered by difficulties regarding the production of large quantities of the protein, the loss of endostatin's biological activity during long-term storage and cumbersome daily administration requirements (6). The present investigation into endostatin production may provide new insight with regards to potential therapeutic endostatin use, and may resolve these difficulties.

In addition, EPCs may also promote regeneration of the vasculature and damaged tissue via increased expression of VEGF, hepatocyte growth factor (HGF) and other growth factors (29). Furthermore, multiple growth factors and cytokines have been demonstrated as being able to recruit EPCs from the EPC rich bone marrow into neovascular sites. Such factors include VEGF, HGF, insulin-like growth factor-1 and others (15). VEGF induces angiogenesis via high-affinity tyrosine kinase receptors, such as VEGF receptor 1 and VEGF receptor 2 (VEGFR-2). VEGFR-2 is a predominant EPC surface marker (30) and mediates the effects of VEGF (31). The interaction between VEGF and VEGFR-2 induces microvascular EC proliferation and migration, thus promoting angiogenesis (31-33). It has been shown that in proliferative diabetic retinopathy, when NV occurs, VEGF expression is increased in the vitreous and sub-retinal fluid (34-36). Therefore, if angiogenic factors, including VEGF, could be successfully inhibited, ocular NV therapies may significantly progress. The present study revealed that the expression of VEGF decreased significantly in the stable, endostatin-transfected EPC line.

As previously aforementioned, it has been hypothesized that EPC may serve as a vehicle for continuous delivery of endostatin to tissues undergoing $\mathrm{NV}$, and the present study successfully developed an endostatin-overexpressing EPC line. The results of this study suggest that the anti-angiogenic and angiogenic agents may achieve autocrine and paracrine effects on angiogenesis by increasing expression of endostatin via a gene transfer system directly targeted to EPC, or by inhibition of VEGF expression via the paracrine effects of endostatin.

The results of the present study suggest that a cell-based therapeutic approach may prove useful in clinical settings for the treatment of patients with $\mathrm{NV}$, as endostatin is a key anti-angiogenic factor and EPCs may be important for the future of NV treatment. EPCs can be modified to produce endostatin via gene transfer in vitro, thus avoiding frequent protein administration. Furthermore, the results of the present study indicate that EPCs constitute an optimal vehicle for the delivery of anti-angiogenic 
protein molecules, as well as providing a strong basis for the development of anti-angiogenic EPCs for NV treatment. This strategy (autologous EPCs with overexpressed anti-angiogenic agents) could be used for each stage of clinical ocular NV as well as several other varieties of ocular vasculopathy. However, the results of the in vitro experiment in the present study cannot be extrapolated directly to human treatment of $\mathrm{NV}$, and therefore animal studies and clinical trials should be performed in order to verify the results of the present study.

\section{Acknowledgements}

Not applicable.

\section{Funding}

This study was supported by Zhejiang Provincial Natural Science Foundation of China (grant no. LQ14H120001), Zhejiang Provincial Natural Science Foundation of China (grant no. LZ18H180001), Zhejiang Key Laboratory Fund of China (grant no. 2011E10006), Project of National Clinical Key Discipline of Chinese Ministry of Health and Zhejiang Province Key Research and Development Program (grant no. 2015C03042), Zhejiang Provincial Natural Science Foundation of China (grant no. LY14H120004), and the National Natural Science Foundation of China (grant nos. 81371001, 81570822, 81500760 and 81500694).

\section{Availability of data and materials}

The analyzed datasets generated during the study are available from the corresponding author on reasonable request.

\section{Authors' contributions}

KY and JA conceived, designed and supervised the research. JA, JHS and TW performed the experiments. JM and LF performed data analyses. JA and KY wrote the manuscript. All authors have read and approved the final manuscript.

\section{Ethics approval and consent to participate}

All of the animal experiments in the present study were approved by the Institutional Animal Care and Ethics Committee of Zhejiang University (Hangzhou, China). The methods in the present study were performed in accordance with approved guidelines and regulations.

\section{Consent for publication}

Not applicable.

\section{Competing interests}

The authors declare that they have no competing interests.

\section{References}

1. Zhang SX and Ma JX: Ocular neovascularization: Implication of endogenous angiogenic inhibitors and potentialtherapy. Prog Retin Eye Res 26: 1-37, 2007.
2. Kong D, Melo LG, Gnecchi M, Zhang L, Mostoslavsky G, Pratt RE and Dzau VJ: Cytokine-induced mobilization of circulating endothelial progenitor cells enhances repair of injured arteries. Circulation 110: 2039-2046, 2004.

3. Hu Y, Davison F, Zhang Z and Xu Q: Endothelial replacement and angiogenesis in arteriosclerotic lesions of allografts are contributed by circulating progenitor cells. Circulation 108: 3122-3127, 2003.

4. Abe Y, Ozaki Y, Kasuya J, Yamamoto K, Ando J, Sudo R, Ikeda M and Tanishita K: Endothelial progenitor cells promote directional three-dimensional endothelial network formation by secreting vascular endothelial growth factor. PLoS One 8: e82085, 2013.

5. O'Reilly MS, Boehm T, Shing Y, Fukai N, Vasios G, Lane WS, Flynn E, Birkhead JR, Olsen BR and Folkman J: Endostatin: An endogenous inhibitor of angiogenesis and tumor growth. Cell 88: 277-285, 1997.

6. Dudek AZ, Bodempudi V, Welsh BW, Jasinski P, Griffin RJ, Milbauer L and Hebbel RP: Systemic inhibition of tumour angiogenesis by endothelial cell-based gene therapy. Br J Cancer 97: 513-522, 2007.

7. Dhanabal M, Ramchandran R, Volk R, Stillman IE, Lombardo M, Iruela-Arispe ML, Simons M and Sukhatme VP: Endostatin: Yeast production, mutants, and antitumor effect in renal cell carcinoma. Cancer Res 59: 189-197, 1999.

8. Mori K, Duh E, Gehlbach P, Ando A, Takahashi K, Pearlman J, Mori K, Yang HS, Zack DJ, Ettyreddy D, et al: Pigment epithelium-derived factor inhibits retinal and choroidal neovascularization. J Cell Physiol 188: 253-263, 2001.

9. Sun JH, Zhang YL, Nie CH, Qian SP, Yu XB, Xie HY, Zhou L and Zheng SS: In vitro labeling of endothelial progenitor cells isolated from peripheral blood with superparamagnetic ironoxide nanoparticles. Mol Med Rep 6: 282-286, 2012.

10. Hristov M, Erl W and Weber PC: Endothelial progenitor cells: Isolation and characterization. Trends Cardiovasc Med 13: 201-206, 2003.

11. Sun W, Zheng L, Han P and Kang YJ: Isolation and characterization of endothelial progenitor cells from Rhesus monkeys. Regen Med Res 2: 5, 2014.

12. Dome B, Dobos J, Tovari J, Paku S, Kovacs G, Ostoros G and Timar J: Circulating bone marrow-derived endothelial progenitor cells: characterization, mobilization and therapeutic considerations in malignant disease. Cytometry A 73: 186-193, 2008.

13. Rafii S, Lyden D, Benezra R, Hattori K and Heissig B: Vascular and haematopoietic stem cells: Novel targets for anti-angiogenesis therapy? Nat Rev Cancer 2: 826-835, 2002.

14. Asahara T, Murohara T, Sullivan A, Silver M, van der Zee R, Li T, Witzenbichler B, Schatteman G and Isner JM: Isolation of putative progenitor endothelial cells for angiogenesis. Science 275: 964-967, 1997.

15. Livak KJ and Schmittgen TD: Analysis of relative gene expression data using real-time quantitative PCR and the 2(-Delta Delta C(T)) method. Methods 25: 402-408, 2001.

16. Friedrich EB, Walenta K, Scharlau J, Nickenig G and Werner N: CD $34 \%$ CD $133^{+} /$VEGFR- $2^{+}$endothelial progenitor cell subpopulation with potent vasoregenerative capacities. Circ Res 98: e20-e25, 2006.

17. Paczkowska E, Gołąb-Janowska M, Bajer-Czajkowska A, Machalińska A, Ustianowski P, Rybicka M,Kłos P, Dziedziejko V, Safranow K, Nowacki P, et al: Increased circulating endothelial progenitor cells in patients with haemorrhagic and ischaemic stroke: The role of endothelin-1. J Neurol Sci 325: 90-99, 2013.

18. Grant MB, May WS, Caballero S, Brown GA, Guthrie SM, Mames RN, Byrne BJ, Vaught T, Spoerri PE, Peck AB, et al: Adult hematopoietic stem cells provide functional hemangioblast activity during retinal neovascularization. Nat Med 8: 607-612, 2002.

19. Tomita M, Yamada H, Adachi Y, Cui Y, Yamada E, Higuchi A, Minamino K, Suzuki Y, Matsumura M and Ikehara S: Choroidal neovascularization is provided by bone marrow cells. Stem Cells 22: 21-26, 2004.

20. Tsai SH, Huang PH, Chang WC, Tsai HY, Lin CP, Leu HB, Wu TC, Chen JW and Lin SJ: Zoledronate inhibits ischemia-induced neovascularization by impairing the mobilization and function of endothelial progenitor cells. PLoS One 7: e41065, 2012.

21. Butler JM, Guthrie SM, Koc M, Afzal A, Caballero S, Brooks HL, Mames RN, Segal MS, Grant MB and Scott EW: SDF-1 is both necessary and sufficient to promote proliferative retinopathy. J Clin Invest 115: 86-93, 2005.

22. Losordo DW and Dimmeler S: Therapeutic angiogenesis and vasculogenesis for ischemic disease: Part II: Cell-based therapies. Circulation 109: 2692-2697, 2004. 
23. Caballero S, Sengupta N, Afzal A, Chang KH, Li Calzi S, Guberski DL, Kern TS and Grant MB: Ischemic vascular damage can be repaired by healthy, but not diabetic, endothelial progenitor cells. Diabetes 56: 960-967, 2007.

24. Liew A, Barry F and O'Brien T: Endothelial progenitor cells: Diagnostic and therapeutic considerations. Bioessays 28 261-270, 2006.

25. Bai YJ, Huang LZ, Zhou AY, Zhao M, Yu WZ and Li XX: Antiangiogenesis effects of endostatin in retinal neovascularization. J Ocul Pharmacol Ther 29: 619-626, 2013.

26. Chen R, Yu H, An YL, Chen HJ, Jia Z and Teng GJ: Endothelial progenitor cells combined with cytosine deaminase-endostatin for suppression of liver carcinoma. J Biomed Nanotechnol 12: 1174-1182, 2016.

27. Baharivand N, Zarghami N, Panahi F, Dokht Ghafari MY, Mahdavi Fard A and Mohajeri A: Relationship between vitreous and serum vascular endothelial growth factor levels, control of diabetes and microalbuminuria in proliferative diabetic retinopathy. Clin Ophthalmol 6: 185-191, 2012.

28. Szary J and Szala S: Intra-tumoral administration of naked plasmid DNA encoding mouse endostatin inhibits renal carcinoma growth. Int J Cancer 91: 835-839, 2001.

29. Otani A, Kinder K, Ewalt K, Otero FJ, Schimmel P and Friedlander M: Bone marrow-derived stem cells target retinal astrocytes and can promote or inhibit retinal angiogenesis. Nat Med 8: 1004-1010, 2002.

30. Hansen TM, Moss AJ and Brindle NP: Vascular endothelial growth factor and angiopoietins in neurovascular regeneration and protection following stroke. Curr Neurovasc Res 5: 236-245, 2008 .
31. Hirashima M, Kataoka H, Nishikawa S, Matsuyoshi N and Nishikawa S: Maturation of embryonic stem cells into endothelial cells in an in vitro model of vasculogenesis. Blood 93: 1253-1263, 1999.

32. Eichmann A, Corbel C, Nataf V, Vaigot P, Bréant C and Le Douarin NM: Ligand-dependent development of the endothelial and hemopoietic lineages from embryonic mesodermal cells expressing vascular endothelial growth factor receptor 2. Proc Natl Acad Sci USA 94: 5141-5146, 1997.

33. Dimmeler S, Dernbach E and Zeiher AM: Phosphorylation of the endothelial nitric oxide synthase at ser-1177 is required for VEGF-induced endothelial cell migration. FEBS Lett 477: 258-262, 2000

34. Connolly DT, Heuvelman DM, Nelson R, Olander JV, Eppley BL, Delfino JJ, Siegel NR, Leimgruber RM and Feder J: Tumor vascular permeability factor stimulates endothelial cell growth and angiogenesis. J Clin Invest 84: 1470-1478, 1989.

35. Dieudonné SC, La Heij EC, Diederen RM, Kessels AG, Liem AT, Kijlstra A and Hendrikse F: Balance of vascular endothelial growth factor and pigment epithelial growth factor prior to development of proliferative vitreoretinopathy. Ophthalmic Res 39: 148-154, 2007.

36. Funatsu H, Noma H, Mimura T, Eguchi S and Hori S: Association of vitreous inflammatory factors with diabetic macular edema. Ophthalmology 116: 73-79, 2009. International (CC BY-NC-ND 4.0) License. 